\title{
A durable coating to prevent stress corrosion effects on the surface strength of annealed glass
}

\author{
Gregorio Mariggiò • Sara Dalle Vacche • \\ Roberta Bongiovanni · Christian Louter • \\ Mauro Corrado
}

Received: 15 June 2021 / Accepted: 31 August 2021 / Published online: 21 September 2021

(C) The Author(s) 2021

\begin{abstract}
The durability of an innovative polymeric coating recently developed by the authors to prevent stress corrosion in annealed glass is herein examined. The coating, having functional graded properties through the thickness, is optimised to provide a very good adhesion with glass and an excellent hydrophobic behavior on the side exposed to the environment, thus creating a good barrier to humidity, which is the triggering agent for stress corrosion. Three scenarios are analysed in terms of ageing: $(i)$ cyclic loading, accomplished by subjecting coated samples to repetitive loading; (ii) natural weathering, performed by exposing coated samples to atmospheric agents; (iii) artificial
\end{abstract}

G. Mariggiò · M. Corrado $(\bowtie)$

Department of Structural, Geothecnical and Building

Engineering, Politecnico di Torino, Corso Duca degli

Abruzzi 24, 10129 Torino, Italy

e-mail: mauro.corrado@polito.it

G. Mariggiò

e-mail: gregorio.mariggio@polito.it

S. Dalle Vacche $\cdot$ R. Bongiovanni

Department of Applied Science and Technology,

Politecnico di Torino, Corso Duca degli Abruzzi 24, 10129

Torino, Italy

e-mail: sara.dallevacche@polito.it

R. Bongiovanni

e-mail: roberta.bongiovanni@polito.it

C. Louter

Institute of Building Construction, Technische Universität

Dresden, August-Bebel-Straße 30, 01219 Dresden,

Germany

e-mail: christian.louter@tu-dresden.de weathering, carried out by exposing coated specimens to fluorescent UV lamps, heat and water. The durability of the coating is assessed indirectly, on the base of its residual effectiveness in preventing stress corrosion, by comparing the bending strength, obtained with the coaxial double ring test, of aged coated glass specimens with that of un-coated and freshly coated specimens. The obtained results prove that the proposed formulation is almost insensitive to cyclic loading, maintains a very good performance in case of natural weathering, whereas is slightly more sensitive to artificial weathering.

Keywords Annealed glass - Stress corrosion Bending strength $\cdot$ Polymeric coating $\cdot$ Durability

\section{Introduction}

Stress corrosion, also known as static fatigue, is a well known phenomenon that affects annealed glass. It consists in a reduction of the material strength caused by the combined action of applied stress and humidity on the silica network that composes glass. The discovery of static fatigue in glass dated back to the end of the nineteenth century, when Grenet observed that the strength of glass depended on the rate of loading or on the load duration (Grenet 1899). Since then, and especially in the second half of the twentieth century, several works contributed to measure the effects of water and water vapor on the sub-critical propagation of microc- 
racks (Wiederhorn 1967; Wiederhorn and Bolz 1967), and to develop chemical- and physical-based models to describe the phenomenon of stress corrosion (Charles and Hillig 1962; Michalske and Freiman 1983). The most accepted theory to account for this phenomenology involves the chemical reaction of water molecules with the silica network, taking place at the tip of surface flaws, although other interpretations have also been provided (Gy 2003).

Solutions to such a problem proposed in the literature include, among others: polymeric and metallic coatings for glass rods and silica lightguides (Bouten 1987; Kurkjian et al. 1993; Chen et al. 1995), silicon grease for the edge strengthening of glass plates (Lindqvist et al. 2012), and graphene coatings (Wang et al. 2016). Recently, the authors developed a functional polymeric coating prepared with an UV-curable resin, a fluorinated methacrylate co-monomer, and a co-reactive silane primer optimised to provide a good barrier to water vapor, hydrophobicity, transparency and adhesion properties (Dalle Vacche et al. 2019b; Mariggiò et al. 2020). Among the many photocurable fluorinated monomers and oligomers available (Vitale et al. 2015), the product used in this work is characterized by a perfluoropolyether chain which is an omniphobic building block, but differently from perfluoroalkylic products, some of which are currently banned, is non-toxic and non-bioaccumulative ACToR (ACToR 2015q3 2021). According to a previous study carried out by the authors, the application of the coating leads to an increase of the bending strength corresponding to a probability of failure of $0.8 \%$ equal to $92 \%$ for new glass and $62 \%$ for aged glass. Besides the very good performance against stress corrosion, the developed coating has some advantages compared to other strengthening techniques and coatings: it is solvent free, it has a very fast curing time, it is low-energy consuming, and it can be easily included in the continuous production systems of flat glass as well as it is available for in-situ applications. Therefore, it could find applications in the production of new structural elements that will be subjected to significantly high long-term loads and in the strengthening of existing elements.

While the effectiveness of the coating in preventing stress corrosion within few days after its application on the glass substrate was proven in a previous work (Mariggiò et al. 2020), the analysis of its durability is the main objective of the present contribution. In this context, three scenarios were analysed to consider most of the possible sources of ageing a glass structural element might be subjected to: (i) cyclic loading, obtained by subjecting coated samples to cyclic loads in order to stress repeatedly the coating and evaluate the appearance of micro-cracking that can reduce the water vapor barrier effect; (ii) natural weathering, performed by exposing coated samples to atmospheric agents; (iii) artificial weathering, carried out by exposing coated specimens to fluorescent UV lamps, heat and water.

\section{Experimental programme}

The experimental programme consisted in the preparation of a set of coated glass specimens for each type of ageing, the ageing of the specimens, and their mechanical testing, aiming to assess the durability of the coating through the evaluation of its residual effectiveness in preventing stress corrosion. The materials and the procedures for ageing and testing are explained in the present section.

\subsection{Materials}

The formulation of the coating, whose details can be found in Dalle Vacche et al. (2019b), consists of a hydrocarbon acrylic resin (Ebecryl ${ }^{\circledR} 130$, by Allnex Belgium SA, Drogenbos, Belgium) and a photoinitiator (Darocur ${ }^{\circledR} 1173$, by BASF, Germany), added with a small amount (1 phr) of a fluorinated methacrylate (Fluorolink ${ }^{\circledR}$ MD700, by Solvay Specialty Polymers, Bollate Milano, Italy). A silane was applied on the glass surface to improve adhesion between the coating and the substrate. The silane was the 3(acryloyloxy) propyltrimethoxysilane, 94\%, supplied by Alfa Aesar (Thermo Fisher (Kandel) GmbH, Karlsruhe, Germany). The formulation herein described was chosen to provide compositionally graded properties to the coating, thus ensuring within a single layer good barrier to water vapor, hydrophobicity, transparency and adhesion with the substrate, as needed for hindering the stress corrosion of glass. The physicalmechanical properties of the coating were studied in previous works (Dalle Vacche et al. 2019a, b), and are summarised in Table 1 for convenience. In particular, Table 1 lists the water vapor transmission rate, 
Table 1 Properties of the coating

\begin{tabular}{lll}
\hline $\begin{array}{l}\mathrm{WVTR}_{25} \\
\left(\mathrm{~g} / \mathrm{m}^{2} / 24 \mathrm{~h}\right)\end{array}$ & $\begin{array}{l}\theta_{\text {water }} \\
\left({ }^{\circ}\right)\end{array}$ & $\begin{array}{l}\text { Adhesion strength } \\
\tau(\mathrm{MPa})\end{array}$ \\
\hline $87.1 \pm 15.8$ & $103.2 \pm 1.6$ & $24.9 \pm 2.8$ \\
\hline
\end{tabular}

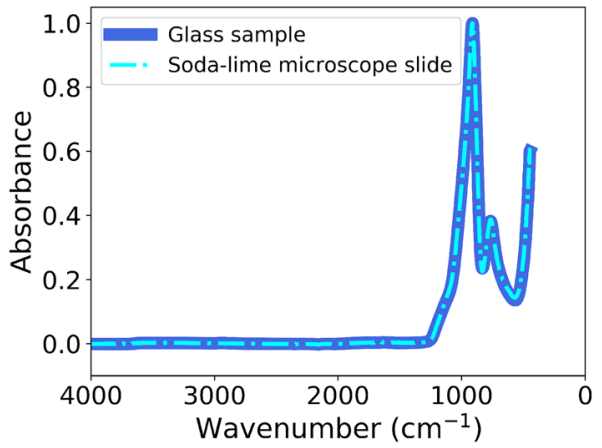

Fig. 1 FTIR-ATR spectra of the glass used in the present work compared to that of a reference soda-lime glass

$\mathrm{WVTR}_{25}$, the water contact angle, $\theta_{\text {water }}$, and the adhesion strength, $\tau$, of the coating.

Square soda-lime silica plates were employed for preparing the specimens. FTIR-ATR (Fourier Transform InfraRed Attenuated Total Reflection) spectroscopy was performed to assess the glass chemical composition. The InfraRed (IR) spectra of the glass used in this study is compared to that of a microscope slide made of low-iron soda-lime silica glass. The two spectra shown in Fig. 1 are perfectly overlapped. Furthermore, the peaks of absorbance at $910 \mathrm{~cm}^{-1}$ and 768 $\mathrm{cm}^{-1}$ are representative of the symmetric and asymmetric vibration of the Si-O-Si bond (Amma et al. 2015).

\subsection{Preparation of test specimens}

The surface of the glass specimens was treated with a silane coupling agent before the application of the coating. The silylation of the glass was performed by immersing the specimens in water solution of the silane for $5 \mathrm{~min}$ at room temperature. The concentration of silane was $0.2 \mathrm{vol} \%$. In order to support silanol condensation, the treated specimens were dried in a oven at $100{ }^{\circ} \mathrm{C}$ for $30 \mathrm{~min}$. Once the silylation process was completed, the surface of the glass samples were covered with the coating by a wire wound bar, and cured
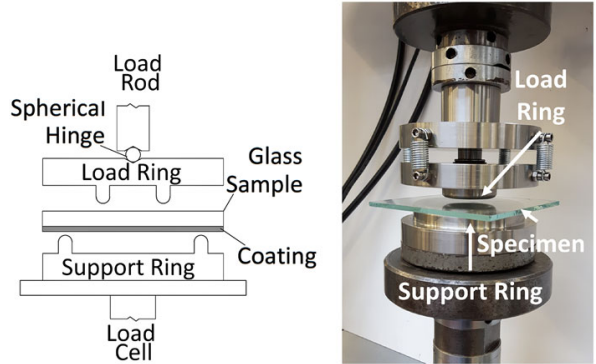

(a)

(b)

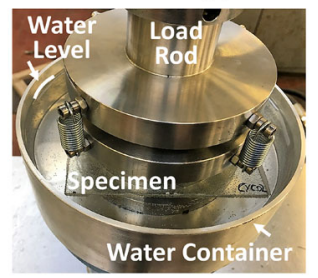

(c)

Fig. 2 Coaxial double ring set-up: a sketch; b global picture of the test rig; $\mathbf{c}$ detail of the water container

with a 5000-EC UV flood lamp system (Dymax Corporation, Torrington, CT, USA) with a medium intensity mercury bulb according to the procedure reported in Dalle Vacche et al. (2019b). After irradiation, a transparent solid film with a thickness of about $50 \mu \mathrm{m}$ was obtained. The coating was applied on the air side of the flat glass specimens, while a self-adhesive film was applied on the tin side in order to hold the fragments together after fracture of the specimens.

\subsection{Cyclic loading}

A set of 22 coated square glass samples having edge length $l=120 \mathrm{~mm}$ and nominal thickness $h=4 \mathrm{~mm}$ were subjected to cyclic equi-biaxial bending loadings by means of the coaxial double ring setup. Such a setup, as shown in Fig. 2, consists of two steel rings of different diameters: the largest one supports the specimens, while the smallest one is used to apply a force normal to the upper surface of the sample, thus resulting in a bi-axial bending stress state in the square sample. The diameters of the support and load rings, $D_{\mathrm{S}}$ and $D_{\mathrm{L}}$, respectively, have been defined as a function of the dimensions of the specimens, in accordance to the ASTM C1499-19 Standard (2019). In detail, they were $D_{\mathrm{S}}=90 \mathrm{~mm}$ and $D_{\mathrm{L}}=40 \mathrm{~mm}$ for $l=120 \mathrm{~mm}$ and $h=4 \mathrm{~mm}$. 


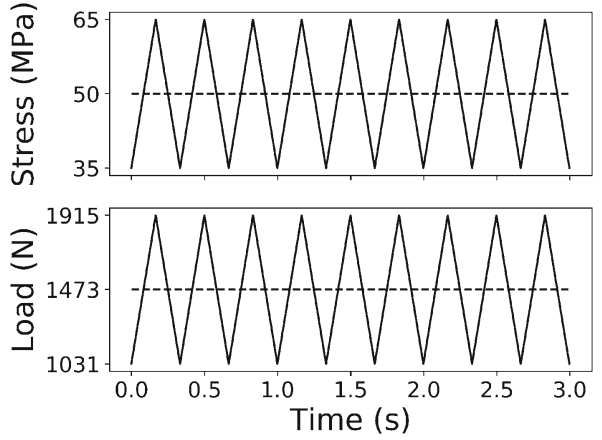

Fig. 3 Schematic diagrams of the cyclic loading

Table 2 Cyclic loading parameters (load and stress amplitude are defined as $\Delta Q=Q_{\max }-Q_{\min }$ and $\Delta \sigma=\sigma_{\max }-\sigma_{\min }$, respectively)

\begin{tabular}{llllll}
\hline Frequency & $\begin{array}{llll}\text { Mean } \\
\text { load }\end{array}$ & $\begin{array}{l}\text { Load } \\
\text { amplitude }\end{array}$ & $\begin{array}{l}\text { Mean } \\
\text { stress }\end{array}$ & $\begin{array}{l}\text { Stress } \\
\text { amplitude }\end{array}$ & $\begin{array}{l}\text { Number } \\
\text { of cycles }\end{array}$ \\
$(\mathrm{Hz})$ & $(\mathrm{N})$ & $\begin{array}{l}\Delta Q \\
(\mathrm{~N})\end{array}$ & $\begin{array}{l}\bar{\sigma} \\
(\mathrm{MPa})\end{array}$ & $\begin{array}{l}\Delta \sigma \\
(\mathrm{MPa})\end{array}$ & $(-)$ \\
\hline 3 & 1473 & 884 & 50 & 30 & 20,000 \\
\hline
\end{tabular}

Cyclic loading was defined by a saw-tooth wave with minimum load equal to $1031 \mathrm{~N}$, maximum load equal to $1915 \mathrm{~N}$ and frequency of $3 \mathrm{~Hz}$ (see Fig. 3). The force controlled cyclic loading was performed for 20,000 cycles. The cyclic load parameters are summarised in Table 2.

The biaxial tensile stress, $\sigma_{1}(t)$, occurring in the central portion of the specimens, on the coating side, was calculated from the load, $Q(t)$, by means of the following equation, provided by ASTM C1499-19 (2019):

$\sigma_{1}(t)=\frac{3 Q(t)}{2 \pi h^{2}}\left[(1-v) \frac{D_{\mathrm{S}}^{2}-D_{\mathrm{L}}^{2}}{2 D^{2}}+(1+v) \ln \frac{D_{\mathrm{S}}}{D_{\mathrm{L}}}\right]$

where: $Q(t)$ is the time varying load, $h$ is the nominal thickness of the specimen, $D_{\mathrm{S}}$ and $D_{\mathrm{L}}$ are the diameters of the support and load rings, respectively, $D$ is the diameter of the glass specimen, and $v=0.22$ is the Poisson's ratio of glass. For a rectangular test specimen, $D$ is the diameter of a circle that expresses the characteristic size of the plate as follows:

$$
D=\frac{l}{0.90961+0.12652 \frac{h}{D_{\mathrm{S}}} 0.00168 \ln \left(\frac{l-D_{\mathrm{S}}}{h}\right)}
$$

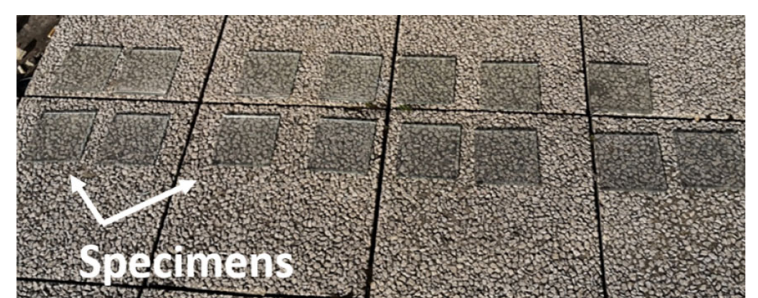

Fig. 4 Set of 15 coated glass specimens exposed to atmospheric agents

where:

$l=0.5\left(l_{1}+l_{2}\right)$

and $l_{1}$ and $l_{2}$ are the lengths of the edges. The fatigue load parameters were chosen to maximise the stretching of the coating without reaching the fracture of the specimen by fatigue or even by simple static loadings. The mean value of $\sigma_{1}(t)$ and the stress amplitude are computed by applying Eq. (1), and reported in Table 2. A large value of the mean stress and a low stress amplitude have been chosen to maintain a high level of tensile stress on the coating side during the entire cyclic load testing, a condition needed to activate the stress corrosion. Furthermore, in order to reproduce an environmental condition as harsh as possible, the support ring and the specimen were immersed in water for the entire duration of the test (see Fig. 2c). The $\mathrm{pH}$ of the water was monitored using full range $\mathrm{pH}$ strips (1-14) and the water was replaced whenever the color of the $\mathrm{pH}$ strip deviated from that of the neutral value, 7, to avoid any effect on the reaction between water molecules and glass. The cyclic loading tests were conducted at room temperature.

\subsection{Natural weathering}

A set of 15 coated square glass samples having $l=120$ $\mathrm{mm}$ and $h=4 \mathrm{~mm}$ were exposed to atmospheric agents for 510 days (17 months), from February 4th 2019, to June 30th 2020, to assess the durability of the coating against natural weathering. The samples were mounted on a frame placed horizontally on the roof of a building of Politecnico di Torino, Corso Duca degli Abruzzi, 24, Torino (Lat: 45.0628, Long: 7.6621, Alt: $254 \mathrm{~m}$. a.s.l) (see Fig. 4). The actual peak to peak variations in temperature and maximum irradiance (SRmax) were between $38.8^{\circ} \mathrm{C}$ (summer) and $-1.5^{\circ} \mathrm{C}$ (winter) and 
Fig. 5 Natural weathering conditions: a maximum, average and minimum daily temperatures; b daily precipitation heights; c maximum solar irradiance (SRmax) and daily solar irradiation (SRtot); d average daily relative humidity
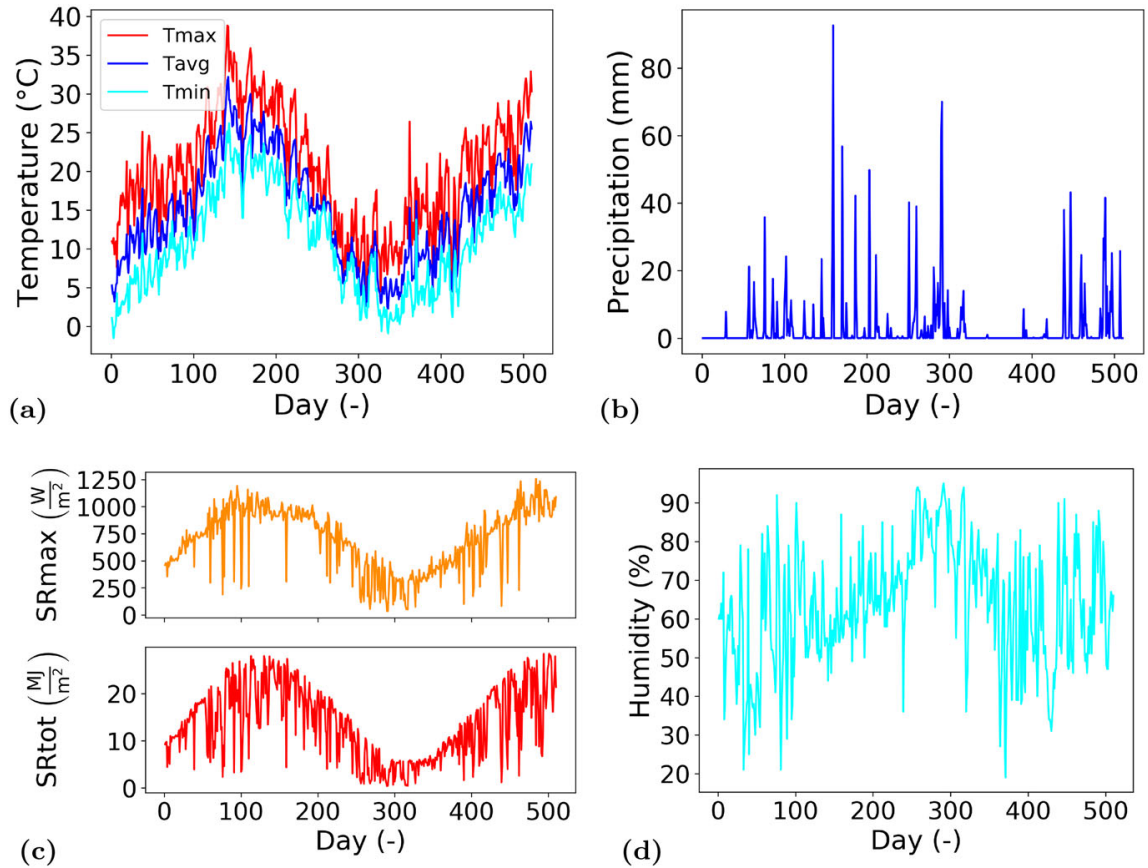

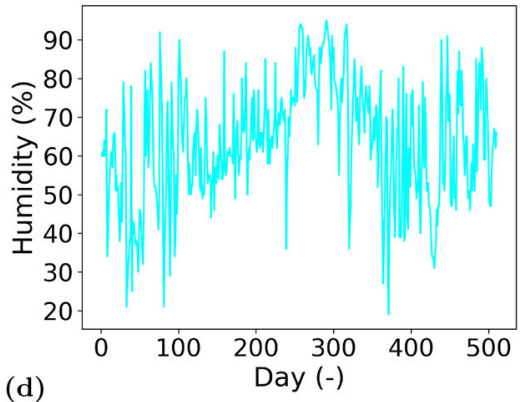

Table 3 Natural weathering parameters: average relative humidity (ARH), average maximum temperature (ATmax), average maximum irradiance (AImax)

\begin{tabular}{lllll}
\hline $\begin{array}{l}\text { Days } \\
\text { of exposure }\end{array}$ & Season & $\begin{array}{l}\text { ARH } \\
(\%)\end{array}$ & $\begin{array}{l}\text { ATmax } \\
{ }^{\circ} \mathrm{C}\end{array}$ & $\begin{array}{l}\text { AImax } \\
\mathrm{W} / \mathrm{m}^{2}\end{array}$ \\
\hline $0-41$ & Winter & 52.27 & 15.63 & 582.85 \\
$42-134$ & Spring & 57.63 & 21.38 & 887.57 \\
$135-227$ & Summer & 63.22 & 29.55 & 866.26 \\
$228-317$ & Autumn & 79.73 & 14.98 & 379.52 \\
$318-407$ & Winter & 61.76 & 13.08 & 456.21 \\
$408-500$ & Spring & 60.90 & 21.41 & 873.65 \\
$501-510$ & Summer & 58.40 & 30.13 & 987.70 \\
\hline
\end{tabular}

between $1256 \mathrm{~W} / \mathrm{m}^{2}$ (summer) and $33 \mathrm{~W} / \mathrm{m}^{2}$ (winter), respectively. Throughout the monitored period, the average relative humidity amounted to $63.46 \%$, while the daily precipitation peaked at $92.66 \mathrm{~mm}$. The daily variations of the weathering conditions to which the specimens were exposed are reported in Fig. 5. The number of days of exposure per season and the average weathering parameters are summarised in Table 3.

The data about the environmental conditions were taken from the Meteorological Station of Atmospheric Physics at the Department of Physics of the University of Turin, Via Pietro Giuria, 1, Torino (Lat: 45.0521,
Long: 7.6814). At the end of the weathering period, all the specimens were removed from the roof, analysed and tested with the coaxial double ring setup.

\subsection{Artificial weathering}

A set of 19 coated square glass samples having $l=75$ $\mathrm{mm}$ and $h=3 \mathrm{~mm}$ were artificially weathered to establish the long-term effects of light, heat and moisture on the mechanical, chemical and physical properties of the coating. Weathering was carried out using a UV accelerated weathering equipment made available by the Cromology Italia S.p.A laboratories (Porcari, Italy). Due to the lacking of a specific standard, the weathering was done following the procedure provided by EN ISO16474-3:2013 (2013), which is the reference Standard for testing the durability of paints and varnishes exposed to outdoor environmental conditions. Weathering cycles lasted $8 \mathrm{~h}$ each, and consisted of two exposure periods: (i) $4 \mathrm{~h}$ of $\mathrm{UV}$ radiation and drying at $60^{\circ} \mathrm{C}$ and (ii) $4 \mathrm{~h}$ of $\mathrm{UV}$ radiation and condensation at $50^{\circ} \mathrm{C}$. The irradiance of the UV lamp was $0.83 \mathrm{~W} / \mathrm{m}^{2} / \mathrm{nm}$, at $340 \mathrm{~nm}$. Condensing humidity is considered the best way to simulate outdoor moisture attack because most of this moisture is the result of dew. The artificial weath- 
Table 4 Artificial weathering conditions per cycle

\begin{tabular}{lllll}
\hline step & $\begin{array}{l}\text { Exposure } \\
\text { period }\end{array}$ & Irradiance & Temperature & $\begin{array}{l}\text { Relative } \\
\text { humidity }\end{array}$ \\
\hline 1 & 4 h dry & $0.83 \mathrm{~W} / \mathrm{m}^{2} / \mathrm{nm}$ & $60 \pm 3{ }^{\circ} \mathrm{C}$ & Not controlled \\
& & $\begin{array}{l}\text { at } 340 \mathrm{~nm} \\
0.83 \mathrm{~W} / \mathrm{m}^{2} / \mathrm{nm}\end{array}$ & $50 \pm 3{ }^{\circ} \mathrm{C}$ & Not controlled \\
& 4 h condensation & & \\
& & & & \\
& &
\end{tabular}

ering conditions are summarised in Table 4 for convenience.

The weathering cycles were conducted for 7 weeks $(1176 \mathrm{~h})$, after which the samples were removed from the ageing machine, analysed and tested with the coaxial double ring setup. In order to track the evolution of the ageing, a specimen was taken every week of exposure to artificial weathering and analysed through visual inspection.

\subsection{Characterisation methods}

After the ageing processes, the coated surface of all the glass samples was visually inspected to identify and localise defects in the coating. Then, different analyses were carried out depending on the ageing process.

Static contact angle measurements were carried out to assess the surface properties of the coated glass samples, before and after the natural weathering. The results have been compared to those of un-coated glass. A Krüss DSA100 instrument (KRÜSS GmbH, Hamburg, Germany) was used, equipped with video camera and image analysis software, with the sessile drop technique. Water was used as testing liquid, and the drops were of $10 \mu \mathrm{l}$. Five measurements were taken on uncoated glass specimens, seven on freshly coated glass specimens and ten on naturally weathered coated glass specimens which had been washed with water and soap and rinsed with distilled water after exposure. It is to be noted that the label "freshly coated glass specimens" identifies the samples tested within few days after the application of the coating.

The transparency of the naturally weathered coated glass samples was also assessed, by means of a JENWAY 6850 UV/Vis (Cole-Parmer, Stone, UK) UVvisible spectrophotometer.

FTIR-ATR spectroscopy was used to track the evolution of the coating ageing for the artificially weath- ered coated samples. At that purpose, this analysis was carried out on specimens exposed for $1,2,3, \ldots$ up to 7 weeks of ageing. A specimen has been taken out from the weathering machine each week and stored in dark and dry conditions up to the end of the seventh week, when the FTIR-ATR spectroscopy was applied to all the specimens. For this reason, only the 13 specimens, out of the initial 19 ones, that reached the seventh week of ageing were mechanically tested to assess the performance of the aged coating.

After the aforementioned non-destructive investigations, mechanical tests were carried out on all the coated glass samples to evaluate the residual effectiveness of the aged coating in protecting the glass surface from stress corrosion. The coaxial double ring set-up was used (see Fig. 2) in accordance to the ASTM C149919 Standard (2019). The dimension of support and load rings for specimens having edge size $l=120 \mathrm{~mm}$ and thickness $h=4 \mathrm{~mm}$, were $D_{\mathrm{S}}=90 \mathrm{~mm}$ and $D_{\mathrm{L}}=40$ $\mathrm{mm}$ as already explained in Sect. 2.3, whereas $D_{\mathrm{S}}$ and $D_{\mathrm{L}}$ for specimens having $l=75 \mathrm{~mm}$ and $h=3$ $\mathrm{mm}$ were $60 \mathrm{~mm}$ and $30 \mathrm{~mm}$, respectively. During the loading tests, the specimens and the support ring were placed into a tank filled with water to create a harsh environment with a steady humidity level. The mechanical tests were carried out by means of a servohydraulic MTS universal testing machine with a load cell capacity of $10 \mathrm{kN}$. A constant displacement rate was applied to induce in the specimens a stress rate equal to $0.15 \mathrm{MPa} / \mathrm{s}$, until failure. A low loading rate was chosen instead of a constant load to have certain and reasonably limited testing times and to facilitate a quantitative comparison between un-coated and coated glass samples. In case the stress corrosion is completely prevented by the coating, in fact, the coated glass samples would never break under a constant load. The value of $0.15 \mathrm{MPa} / \mathrm{s}$, which caused fracture of the samples within 6 to $14 \mathrm{~min}$, was chosen based on evidences that such a rate is low enough to reveal the effects of stress 


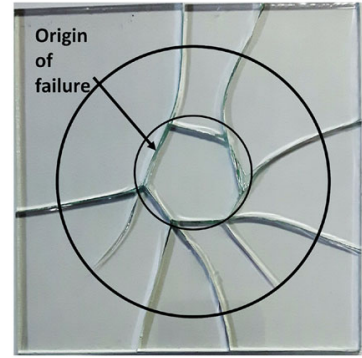

(a)

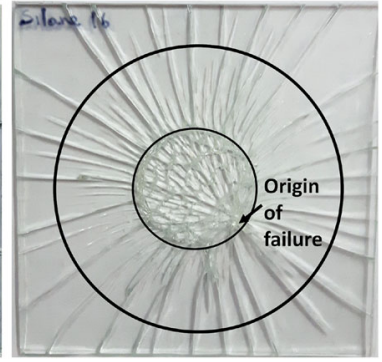

(b)
Fig. 6 Crack patterns obtained from: a an un-coated specimen, which exhibited a bending strength of $35 \mathrm{MPa}$, and $\mathbf{b}$ a coated specimen, which developed a bending strength of $110 \mathrm{MPa}$

corrosion (Lindqvist et al. 2012; Mariggiò et al. 2020). The bending strength, $\sigma_{\mathrm{f}}$, was calculated from the fracture load, $Q_{\mathrm{f}}$, by means of Eq. (1) and the results were compared to those of freshly coated and un-coated glass samples, reported in Mariggiò et al. (2020). Examples of the crack pattern typically obtained with the coaxial double ring test are shown in Fig. 6 for two extreme values of bending strength: the higher is the bending strength, the smaller is the average fragments size. It is worth noticing that the test is valid only if the origin of fracture is located inside the footprint of the loading ring.

\subsection{Statistical analysis of strength data}

The randomly distributed micro-cracks on the glass surface and their randomly distributed geometry and depth cause a very strong scattering of the glass bending strength. Therefore, a statistical inference of the strength data was performed.

The glass strength population can be represented by a two parameter Weibull distribution function:

$P_{\mathrm{f}}=1-\exp \left[-\left(\frac{\sigma_{\mathrm{f}}}{\theta}\right)^{\beta}\right]$

where $P_{\mathrm{f}}$ is the cumulative distribution function of failure, and $\beta$ and $\theta$ are the Weibull shape and scale parameters, obtained by the best-fitting of experimental data. The Weibull distribution function can be linearized by taking the logarithm twice:

$\ln \left(\ln \left(\frac{1}{1-P_{\mathrm{f}}}\right)\right)=\beta \ln \left(\sigma_{\mathrm{f}}\right)-\beta \ln (\theta)$
According to EN 12603 (2002), $\beta$ and $\theta$ parameters are calculated with the good linear unbiased estimators method:

$$
\begin{aligned}
& \hat{\beta}=\frac{n k_{\mathrm{n}}}{\frac{s}{n-s} \sum_{i=s+1}^{n} \ln \sigma_{i}-\sum_{i=1}^{s} \ln \sigma_{i}} \\
& \hat{\theta}=\exp \left[\frac{1}{n} \sum_{i=1}^{n} \ln \sigma_{i}+0.5772 \frac{1}{\hat{\beta}}\right]
\end{aligned}
$$

where: $n$ is the sample size, $s$ is the largest integer less than $0.84 n$, and the values of $k_{n}$, estimated as a function of the sample size $n$, are listed in Table 3 of EN 12603 (2002).

Strength data, $\sigma_{\mathrm{f}}$, are ranked in ascending order $(i=1$ to $n$ ) to build an Ordered Sample and, then, a probability of failure is assigned to each value $\sigma_{i}$ of the Ordered Sample by means of probability estimators $\hat{G}_{i}$ :

$\hat{G}_{i}=\frac{i-0.3}{n+0.4}$

Finally, each point $\left(\sigma_{\mathrm{f}}, \hat{G}_{i}\right)$ is plotted into the Weibull diagram, which relates the probability of failure to the fracture stress.

\section{Results and discussion}

In the present section, the results of the tests carried out to evaluate the effects of ageing on the performance of the coating against stress corrosion are presented and discussed. The performance of the aged specimens has been assessed against the performance of un-coated specimens and freshly coated specimens, i.e. samples tested within few days after the application of the coating, whose results can be found in Dalle Vacche et al. (2019b) and Mariggiò et al. (2020).

After the ageing processes, all the specimens were cleaned and inspected by naked-eye to localize defects in the coating. The surface damage was visually examined with the specimen placed on a table under regular ceiling-lighting conditions. No evident imperfections were detected on the coated surfaces of cyclic loaded and naturally weathered samples, whereas artificially weathered specimens exposed for six and seven weeks exhibited cracking and delamination of the coating (see Fig. 7). 


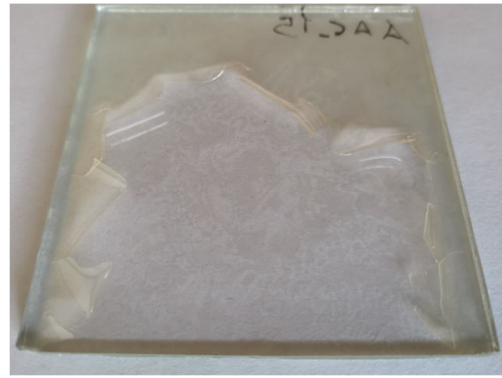

Fig. 7 Qualitative assessment, by visual inspection, of coating deterioration after seven weeks of exposure to artificial weathering

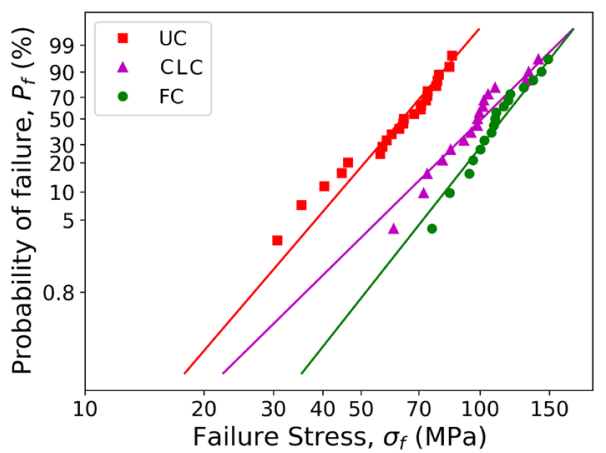

Fig. 8 Weibull distribution functions for the bending strength of un-coated (UC), freshly coated (FC) and cyclic loaded coated (CLC) glass samples

\subsection{Effects of cyclic loading}

The bending strength of each cyclic loaded coated specimen was evaluated by means of the coaxial double ring test directly after the cyclic loading procedure, to avoid possible crack healing effects. The Weibull diagram obtained from the set of specimens is shown in Fig. 8, where it is compared to the Weibull diagrams of the bending strength of un-coated and freshly coated samples.

A first qualitative analysis of the experimental data points suggests that the coating has a high durability against cyclic loading since the distribution of the probability of failure of cyclic loaded coated specimens is very close to that of freshly coated specimens. Straight lines, which represent the linearised Weibull distribution function, fit well the experimental data sets, indicating that the Weibull distribution can be used to interpret them correctly. The curve that best fits the data points of cyclic loaded coated specimens (purple triangular markers) is characterised by $\hat{\beta}=4.34$ and $\hat{\theta}=109.99 \mathrm{MPa}$, that of un-coated specimens (red square markers) is defined by $\hat{\beta}=5.16$ and $\hat{\theta}=68.25$ $\mathrm{MPa}$, while that of freshly coated specimens (green circular markers) by $\hat{\beta}=5.60$ and $\hat{\theta}=121.80 \mathrm{MPa}$. The effectiveness of the coating can be quantified by the scale parameter $\hat{\theta}$, which represents the strength associated to a probability of failure of $63.2 \%$.

Furthermore, the comparison among the Weibull shape parameters, $\hat{\beta}$, allows to derive very interesting insights on the behaviour of cyclic loaded coated specimens. As expected, the parameter $\hat{\beta}$, which represents the slope of the linearised Weibull diagram and thus describes the strength scatter as well as the dispersion of the size of the critical surface defects, is almost the same for freshly coated and un-coated glass samples, whereas it differs for cyclic loaded samples. In particular, the data points of cyclic loaded coated and freshly coated samples are almost paired for a probability of failure $P_{\mathrm{f}}>70 \%$, whereas they diverge for low values of $P_{\mathrm{f}}$. It is opinion of the authors that the variation of $\hat{\beta}$ is not sign of a deterioration of the coating. On the contrary, it is a proof of a very good performance of the coating during the ageing process. Let us assume that the coating is able to completely prevent stress corrosion (static fatigue) during the ageing process. In that case, the specimen is subjected only to dynamic fatigue, which can be described by a classical Paris-Erdogan's law (Paris and Erdogan 1963). However, as it is well known, the sub-critical propagation of cracks by fatigue occurs only when the stress intensity factor at the crack tip overcomes a threshold, which is a material property. Since the mean stress and the stress amplitude were the same for all the specimens, only the largest critical surface flaws propagated by fatigue, whereas the smallest ones were not sufficiently stressed. Consequently, the scatter of the size of the critical defects increased, leading to a decrease of the parameter $\hat{\beta}$. In that regard, it has to be remarked that five specimens broke during the cyclic loading, after a number of cycles in the range 4,000 to 15,000 , probably due to the fact that the critical flaws were large enough to propagate by dynamic fatigue up to reaching the condition of unstable crack propagation.

In the absence of coating, or in the case of a fast deterioration of the coating, the specimen would be subjected to both static and dynamic fatigue. In such a circumstance, the effect of stress corrosion (static fatigue) prevails by far on the effect of dynamic fatigue, especially for small defects. The crack propagation per 
cycle can be described by the Evans' law (Evans and Fuller 1974):

$\frac{d a}{d N}=\lambda g A \bar{K}_{\mathrm{I}}^{n}$

where $g$ and the crack velocity parameters $A$ and $n$ depend on the loading conditions, the material, the temperature and the environment, $\lambda$ is the period of the cyclic loading, and $\bar{K}_{\mathrm{I}}$ is the average stress intensity factor per cycle

$\bar{K}_{\mathrm{I}}=\bar{\sigma} Y \sqrt{\pi a}$

being $\bar{\sigma}$ the average stress, $Y$ a geometry and loading factor, and $a$ the crack depth. Therefore, the crack propagation rate strongly depends on the initial crack depth, since it varies directly as $a^{(n / 2)}$, the deeper the initial surface defect, the faster the crack propagation rate.

An example is herein provided to highlight the fact that most of the cyclic loaded glass samples would have fractured during cyclic loading had they not been covered by the developed coating. The cyclic loaded coated and freshly coated samples were prepared with glass plates coming from the same batch and, therefore, we can reasonably assume that they had the same initial surface defects density and size. Now, assuming that freshly coated glass samples were not affected by stress corrosion, the size of the critical surface defect, i.e., the one that lead to fracture, can be obtained by the relationship between fracture stress and crack size derived from linear elastic fracture mechanics:

$a_{\mathrm{cr}}=\frac{1}{\pi}\left(\frac{K_{\mathrm{IC}}}{Y \sigma_{\mathrm{f}}}\right)^{2}$

where the value of the fracture toughness $K_{\text {IC }}$, ranging from 0.72 to $0.82 \mathrm{MPa} \mathrm{m}{ }^{1 / 2}$ for soda-lime glass, is set for this example to $0.75 \mathrm{MPa} \mathrm{m}^{1 / 2}$, and the geometry and loading factor $Y$ is equal to 1.12 for straight front plane edge cracks in a semi-infinite solid (Overend and Zammit 2012). The bending strength of the freshly coated glass referred to a probability of failure $P_{\mathrm{f}} \leq 63.2 \%$ is $\sigma_{\mathrm{f}} \leq \hat{\theta}_{\mathrm{FC}}=121.80 \mathrm{MPa}$ and, therefore, by Eq. (11) it can be inferred that the $63.2 \%$ of the statistical population of the critical surface defects has an initial depth $a_{\mathrm{cr}} \geq 9.62 \mu \mathrm{m}$. For constant environmental conditions, the parameter $A$ in Eq. (9) may be expressed as (Haldimann et al. 2008):

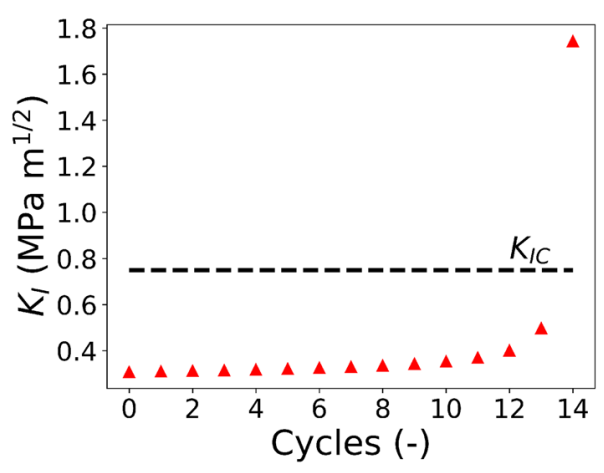

Fig. 9 Trend of the stress intensity factor $K_{\mathrm{I}}$ under cyclic loading in the presence of both static and dynamic fatigue: initial depth of the critical surface flaw $a_{\mathrm{cr}}=9.62 \mu \mathrm{m}$, mean stress $\bar{\sigma}=50$ $\mathrm{MPa}$, stress amplitude $\Delta \sigma=30 \mathrm{MPa}$

$A=\frac{v_{0}}{K_{\mathrm{IC}}^{n}}$

where $v_{0}=30 \mathrm{~mm} / \mathrm{s}$ and $n=16$ are representative of glass permanently immersed in water (Haldimann 2006). Evans and Fuller (1974) showed that, for a saw-tooth stress wave, $g$ parameter in Eq. (9) may be approximated as:

$g \simeq\left(\frac{2^{n}}{n+1}\right) \frac{\exp \left[\frac{(n-1)}{4} \frac{\Delta K_{\mathrm{I}}}{\bar{K}_{\mathrm{I}}}\right]}{\exp \left[\frac{(n-1)}{2}\right]}$

being $\Delta K_{\mathrm{I}}$ the stress intensity factor amplitude per cycle. Setting the initial depth of the critical surface flaw $a_{\mathrm{cr}}=9.62 \mu \mathrm{m}$ and the period $\lambda=1 / 3 \mathrm{~s}$, the implementation of Eq. (9) in a numerical algorithm shows that a glass sample would fail within 13 cycles, as shown in Fig. 9, if subjected to cyclic loading conditions as described in Sect. 2.3 and summarised in Table 2. This example illustrates that much more than five samples would have fractured within 20,000 cycles had stress corrosion occurred on the covered glass specimens.

Certainly, Eq. (9) can be applied only when the stress intensity factor overcome the threshold for sub-critical crack growth, $K_{\mathrm{I} \text {,th }}$, which can be assumed equal to 0.25 MPa $\mathrm{m}^{1 / 2}$ as per Haldimann (2006). The dimension of the initial surface flaw for which sub-propagation does not occur can be calculated through Eq. (11), by substituting $K_{\mathrm{IC}}$ with $K_{\mathrm{I} \text {,th }}$ and $\sigma_{\mathrm{f}}$ with the mean stress of the cyclic loading $\bar{\sigma}=50 \mathrm{MPa}$. It is obtained $a_{\mathrm{th}}=$ 


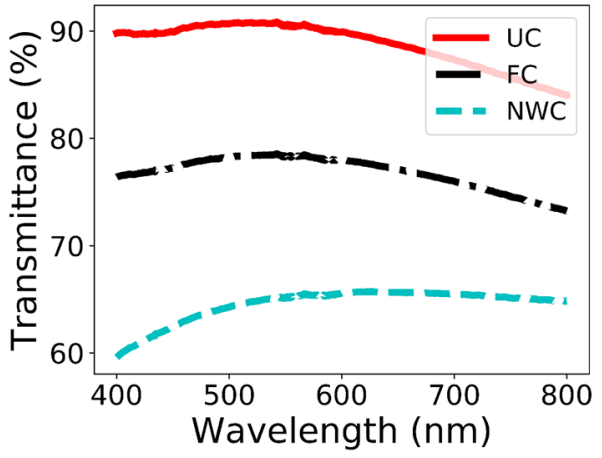

Fig. 10 Visible spectra of un-coated (UC), freshly coated (FC) and naturally weathered coated (NWC) glass samples

$6.34 \mu \mathrm{m}$ for the present example. Therefore, in case the coating had not been applied, only the glass samples having $a_{\mathrm{cr}} \leq a_{\mathrm{th}}=6.34 \mu \mathrm{m}$ would have survived to the cyclic loading.

In conclusion, besides being durable to cyclic loading, the coating can be used to derive the pure dynamic fatigue behaviour of glass, which cannot be obtained otherwise because of the concomitant effect of static fatigue.

\subsection{Effect of natural weathering}

Visible spectra analysis was performed on the naturally weathered coated samples in order to evaluate the transparency, one of the most peculiar and appreciated property of glass, also in structural applications. The percentage of transmittance of wavelengths in the range of visible light is shown in Fig. 10, where it is compared to those of un-coated glass and freshly coated glass. The transmittance is higher than $60 \%$ in the visible range for all the glass samples, which means that the transparency of glass, equal to about $90 \%$ in absence of coating, is sensibly reduced, but still remains above the value of the minimum acceptable glazing transmittance that, according to a study carried out by Boyce et al. (1995), falls within the range $25 \%$ to $38 \%$.

The wettability of the coated surface of the glass samples was estimated through water static contact angle measurements. As the contact angle of the droplets with the surface rises, the hydrophobicity increases (Arkles 2006). The average water contact angles for un-coated glass, freshly coated glass and naturally weathered coated glass specimens are reported in Table 5. While the glass is quite wettable by water
Table 5 Water static contact angles

\begin{tabular}{ll}
\hline Glass samples & $\theta_{\text {water }}\left(^{\circ}\right)$ \\
Un-coated glass & $23.9 \pm 1.8$ \\
Freshly coated glass & $103.2 \pm 1.6$ \\
Naturally weathered coated glass & $60.0 \pm 8.5$ \\
\hline
\end{tabular}

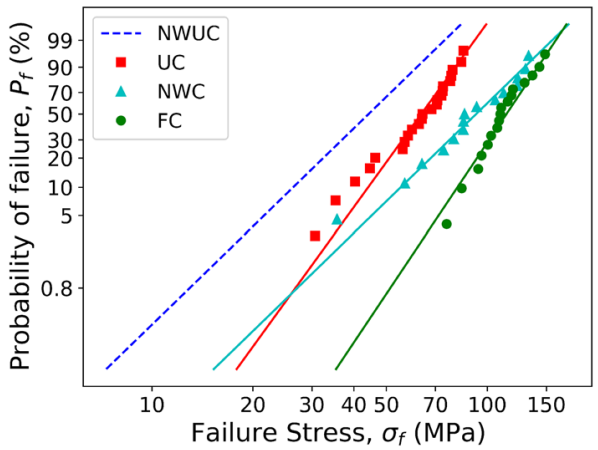

Fig. 11 Weibull distribution functions for the bending strength of un-coated (UC), freshly coated (FC), and naturally weathered coated (NWC) glass samples

and shows a contact angle of $23.9^{\circ}$ after a simplified cleaning protocol is applied on the tested surface, the freshly coated glass exhibits a contact angle of $103.2^{\circ}$ : largely exceeding $90^{\circ}$, the value indicates that the surface is quite hydrophobic as expected by a gradient coating where the fluorine component is preferentially concentrated at the surface. After 510 days of natural weathering, the coating wettability increases and the contact angle value is found as low as $60^{\circ}$. This value is similar to that measured on a coating made of the pure resin without the addition of the fluorinated comonomer (Dalle Vacche et al. 2019a), thus it means that the surface composition has changed due to outdoor exposure. This is in agreement with recent studies assessing the rearrangements of polymers in dependence of the environment. When coatings containing a low amount of a fluorinated component are prepared and maintained in dry air, the fluorinated chains segregate at the coating surface, and assure hydrophobicity. When the coating is in contact with a polar solvent such as water, the fluorinated moieties can easily rearrange and cause an increase of wettability (Trusiano et al. 2019).

The Weibull diagrams for un-coated, freshly coated and naturally weathered coated glass specimens are shown in Fig. 11. The data points of naturally weathered 
Fig. 12 FTIR-ATR spectra taken on the surface of freshly coated glass and coated glass that had been artificially weathered for 1 , $2,3,4,6$, and 7 weeks

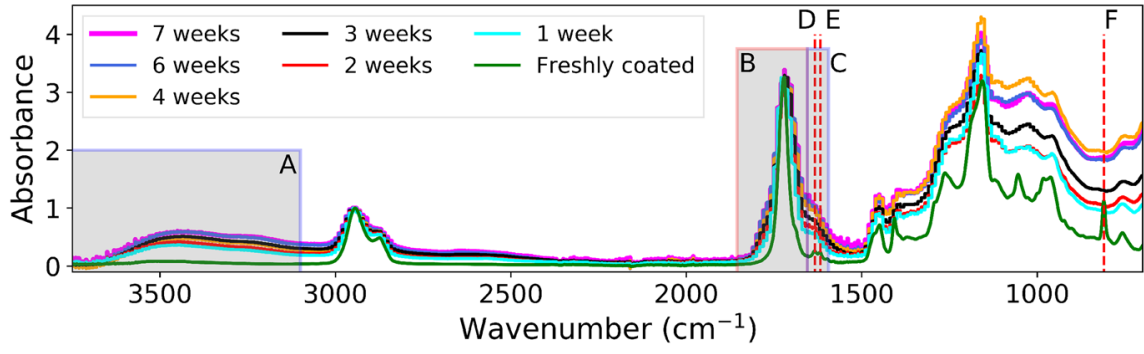

coated specimens (light blue triangles) are well fitted by a Weibull distribution function having $\hat{\beta}=3.63$ and $\hat{\theta}=102.54 \mathrm{MPa}$. Although the $\hat{\theta}$ value for naturally weathered coated samples is greater than that for uncoated samples and very close to that for freshly coated samples, the decrease of the $\hat{\beta}$ value has a quite negative effect, especially on the evaluation of the design bending strength, i.e. a characteristic value having a probability of failure lower than $5 \%$. Our conjecture is that the decrease of $\hat{\beta}$ is again due to a variation of the critical defect size distribution, rather than a consequence of a reduced performance of the coating. In the latter case, in fact, the Weibull curve should undergo a simple translation with respect to the reference ones, without any change in slope. Although the coating applied on the naturally weathered coated samples was not visibly damaged after weathering, hail and other contaminants impacts may have resulted in new and larger flaws on the surface of the glass samples (Jenkins and Mathey 1982; Corrado et al. 2017). As a result, the dispersion of the defect population in naturally weathered coated glass increased, leading to a decrease in the $\hat{\beta}$ value.

A more consistent comparison should have been done with naturally weathered un-coated glass specimens, subjected to the same weathering conditions. Unfortunately, such a set of specimens was not included in the present study. However, for the sake of clarity, an hypothetical Weibull distribution for the bending strength of naturally weathered un-coated glass specimens is shown in Fig. 11 (dashed blue line). Given that naturally weathered un-coated and coated samples should have similar surface defect density and size, the two distributions have the same $\hat{\beta}$ value. The parameter $\hat{\theta}$ for the hypothetical distribution was determined by assuming that the naturally weathered un-coated and coated probability distributions are spaced apart as well as the un-coated and freshly coated distributions are. Under this hypothesis, the beneficial effect of the coating, also for low values of probability of failure, is evident.

\subsection{Effect of artificial weathering}

Figure 12 shows the FTIR-ATR spectra collected on the coating surface at different weathering time. All along the weathering process, there is a steady increase of the $3700-3100 \mathrm{~cm}^{-1}$ band (region A) and of the shoulder at $1640 \mathrm{~cm}^{-1}$ (region $\mathrm{C}$ ): the signals are related to the vibrations of $-\mathrm{OH}$ groups and may indicate water adsorption onto the coating (Wang et al. 2004). The broadening of the $\mathrm{C}=\mathrm{O}$ peak in the 1850-1650 $\mathrm{cm}^{-1}$ region (region $\mathrm{B}$ ) may be associated to oxidation phenomena, i.e. degradation of the coating in the presence of air under light. Interesting information can be gathered observing the doublet band at $1634 \mathrm{~cm}^{-1}$ and $1618 \mathrm{~cm}^{-1}$ (peaks D and E) and the band at 810 $\mathrm{cm}^{-1}$ (peak F) present for freshly coated glass and disappearing after one week of exposure. These signals are due to the double bond of the methacrylate group characterising the oligomer used for the preparation of the coating and subjected to curing through the double bonds' reaction. Therefore, the coating is not completely crosslinked at the end of the curing process (presence of the above-mentioned bands); while, after the first two ageing weeks, when these peaks disappear, the conversion is complete (Dalle Vacche et al. 2019a; Bongiovanni et al. 2012).

As explained in Sect. 2.5, the specimens used to analyse the effects of artificial weathering had edge length $l=75 \mathrm{~mm}$ and thickness $h=3 \mathrm{~mm}$, instead of $120 \mathrm{~mm}$ and $4 \mathrm{~mm}$, respectively. A comparison with the probability of failure of specimens having $l=120$ $\mathrm{mm}$ and $h=4 \mathrm{~mm}$ would have not been coherent and, therefore, a set of 18 un-coated specimens with size $75 \mathrm{~mm}$ was tested with the coaxial double ring setup. The Weibull diagrams for the bending strength of un- 


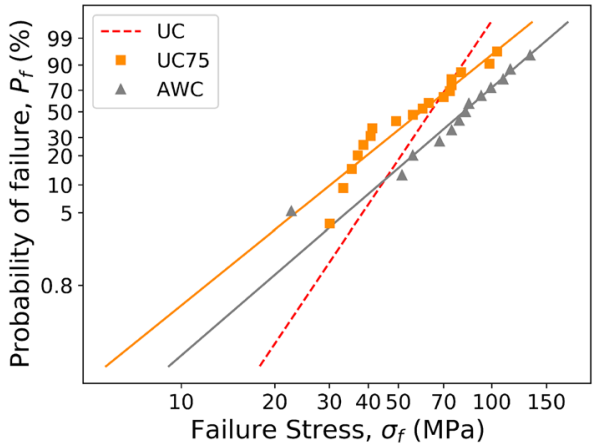

Fig. 13 Weibull distribution functions for the bending strength of artificially weathered coated glass samples (AWC) and uncoated glass samples (UC75) with edge size $l=75 \mathrm{~mm}$

coated specimens having size of $75 \mathrm{~mm}$ and artificially weathered coated glass specimens are shown in Fig. 13. In order to highlight the aforementioned inconsistency between specimens of different size, the Weibull distribution function of un-coated specimens having $l=120$ $\mathrm{mm}$ is also shown in Fig. 13 (red dashed line).

The parameters of the Weibull distribution functions that best fit the data points are: $\hat{\beta}=3.0$ and $\hat{\theta}=91.9 \mathrm{MPa}$ for artificially weathered coated specimens (gray triangles), $\hat{\beta}=2.8$ and $\hat{\theta}=67.5 \mathrm{MPa}$ for un-coated specimens (orange square). The increase of bending strength is evident, although it was quite unexpected after the initial visual inspection of the specimens, which revealed an almost complete detachment of the coating after seven weeks of exposure to artificial weathering (see Fig. 7). A plausible explanation is that the silane coupling agents used to improve the adhesion of the coating on the substrate reached the tips of the surface defects, increasing the hydrophobicity of the glass in the spots where the stress corrosion reac- tion can occur. The property of the silane to alter the wettability of glass by inducing the surface hydrophobicity has already been proven by several studies (Dalle Vacche et al. 2019a; Arkles et al. 2009; Wei et al. 1993).

The statistical data of all the sets of specimens analysed in this study are reported in Table 6. They include, for each series of tests, the number of specimens that fractured in an acceptable way, the Weibull shape parameter $\hat{\beta}$, the Weibull scale parameter $\hat{\theta}$ and the coefficient of variation $\hat{C V}$.

\section{Conclusions}

The durability of an UV-cured polymeric coating optimized to prevent glass stress corrosion has been examined. Concerning the cyclic loading, the coating resulted to be insensitive to repetitive loads, being its performance in preventing stress corrosion remained almost intact. However, the coating cannot hinder the dynamic fatigue taking place in case a sufficiently high level of stress is achieved at the tip of the surface flaws, as it was in the cyclic tests carried out in this study. The sub-critical growth of the critical surface flaws by fatigue has been evidenced by a reduction of the $\hat{\beta}$ parameter of the Weibull distribution for the bending strength, which, therefore, is not related to a reduced performance of the coating.

The natural weathering had its main effect on the optical properties of the coating, in the sense that it caused a reduction of the transparency, although it remained on acceptable values. On the other hand, the effectiveness of the coating in preventing stress corrosion was almost fully preserved. Also in this case, the reduction of the $\hat{\beta}$ parameter of the Weibull distribution for the bending strength has to be associated to a

Table 6 Statistical data of the experimental results

\begin{tabular}{|c|c|c|c|c|c|c|}
\hline $\begin{array}{l}\text { Id. } \\
\text { code }\end{array}$ & $\begin{array}{l}\text { Edge } \\
\text { size } \\
(\mathrm{mm})\end{array}$ & $\begin{array}{l}\text { Type of } \\
\text { samples }\end{array}$ & $\begin{array}{l}\text { No. of } \\
\text { valid } \\
\text { samples }\end{array}$ & $\begin{array}{l}\text { Weibull } \\
\text { param. } \\
\hat{\beta}\end{array}$ & $\begin{array}{l}\text { Weibull } \\
\text { param. } \\
\hat{\theta}(\mathrm{MPa})\end{array}$ & $\begin{array}{l}\hat{C V} \\
(\%)\end{array}$ \\
\hline UC & 120 & Un-coated & 23 & 5.2 & 68.3 & 24.2 \\
\hline $\mathrm{FC}$ & 120 & Freshly coated & 17 & 5.6 & 121.8 & 17.7 \\
\hline CLC & 120 & Cyclic loaded coated & 17 & 4.3 & 110.0 & 22.1 \\
\hline NWC & 120 & Naturally weathered coated & 15 & 3.6 & 102.5 & 31.0 \\
\hline UC75 & 75 & Un-coated & 18 & 2.8 & 67.5 & 38.1 \\
\hline AWC & 75 & Artificially weathered coated & 13 & 3.0 & 91.9 & 35.6 \\
\hline
\end{tabular}


variation in the distribution of the critical defect size due to the impact of hail stones and other particles.

Finally, the effect of the artificial weathering on the durability of the coating is more pronounced. There was no evidence of damage in the coating until five weeks of exposure, whereas it was almost completely detached after seven weeks of exposure. It has to be remarked that the conditions applied for the artificial weathering were very severe in terms of temperature, humidity and UVlight. Nevertheless, a not-negligible residual capacity to prevent stress corrosion was observed. A possible explanation is that the silane used to pre-treat the surface of the glass reached the tips of the surface defects, increasing the hydrophobicity of the glass in the spots where the stress corrosion reaction might occur.

In conclusion, even though only the application on the air side has been investigated so far and slight modifications in the formulation of the coating can be brought to further improve its durability, the current formulation has already shown a very good performance, which makes it very promising for future practical applications. Further studies will be carried out to assess the resistance of the coating to abrasions and scratches, to better evaluate its optical band gap, and to analyse its performance when applied on the cut edges of glass plates.

Acknowledgements The financial support of Politecnico di Torino and Compagnia di San Paolo to the project "GLASS \& CO - Enhancing the effective strength of structural glass with functional coatings" is gratefully acknowledged. The authors also wish to thank Eng. Luisa Gaiero for her help in preparing the specimens and Eng. Simona Bargiacchi and Dr. Luca Contiero from Cromology Italia S.p.A. for their active contribution to the project GLASS \& CO, and in particular for carrying out the artificial weathering of the glass specimens.

Funding Open access funding provided by Politecnico di Torino within the CRUI-CARE Agreement.

\section{Declarations}

Conflict of interest The authors have no conflicts of interest to declare that are relevant to the content of this article.

Open Access This article is licensed under a Creative Commons Attribution 4.0 International License, which permits use, sharing, adaptation, distribution and reproduction in any medium or format, as long as you give appropriate credit to the original author(s) and the source, provide a link to the Creative Commons licence, and indicate if changes were made. The images or other third party material in this article are included in the article's Creative Commons licence, unless indicated otherwise in a credit line to the material. If material is not included in the article's Creative Commons licence and your intended use is not permitted by statutory regulation or exceeds the permitted use, you will need to obtain permission directly from the copyright holder. To view a copy of this licence, visit http://creativecommons.org/licenses/ by $/ 4.0 /$.

\section{References}

ACToR 2015q3 (2021) Aggregated computational toxicology online resource. https://actor.epa.gov/actor/chemical. xhtml? casrn $=69991-67-9$

Amma, S., Luo, J., Pantano, C.G., Kim, S.H.: Specular reflectance (SR) and attenuated total reflectance (ATR) infrared (IR) spectroscopy of transparent flat glass surfaces: A case study for soda lime float glass. J. Non-Cryst. Solids 428, 189-196 (2015)

Arkles, B.: Hydrophobicity, hydrophilicity and silanes. Paint Coat. Ind. 22, 114 (2006)

Arkles, B., Pan, Y., Kim, Y.M.: The role of polarity in the structure of silanes employed in surface modification. In: Mittal, K. (ed.) Silanes and Other Coupling Agents, vol. 5, pp. 51-64. CRC Press, Boca Raton (2009)

ASTM C1499-19, : Standard test method for monotonic equibiaxial flexural strength of advanced ceramics at ambient temperature. ASTM International, West Conshohocken (USA) (2019)

Bongiovanni, R., Medici, A., Zompatori, A., Garavaglia, S., Tonelli, C.: Perfluoropolyether polymers by UV curing: design, synthesis and characterization. Polym. Int. 61, 65173 (2012)

Bouten, P.C.P.: Lifetime of pristine optical fibres. Technische Universiteit Eindhoven, Eindhoven, The Netherlands (1987)

Boyce, P., Eklund, N., Magnum, S., Saalfield, C., Tang, L.: Minimum acceptable transmittance of glazing. J. Light. Res. Technol. 27, 145-152 (1995)

Charles, R.J., Hillig, W.B.: The kinetics of glass failure by stresscorrosion. In: Symposium on Mechanical Strength of Glass and Ways of Improving It, pp. 511-527. Union Scientifique Continentale du Verre, Charleroi, Belgium (1962)

Chen, X.M., Ellis, B., Wang, F., Seddon, A.B.: Strengthening of glass rods with ormosil polymeric coatings. J. Non-Cryst. Solids 185, 1-17 (1995)

Corrado, M., Infuso, A., Paggi, M.: Simulated hail impacts on flexible photovoltaic laminates: testing and modelling. Meccanica 52, 1425-1439 (2017)

Dalle Vacche, S., Forzano, S., Vitale, A., Corrado, M., Bongiovanni, R.: Glass lap joints with UV-cured adhesives: use of a perfluoropolyether methacrylic resin in the presence of an acrylic silane coupling agent. Int. J. Adhes. Adhes. 92, 16-22 (2019a)

Dalle Vacche, S., Mariggiò, G., Vitale, A., Bongiovanni, R., Corrado, M.: Compositionally graded hydrophobic UV-cured coatings for the prevention of glass stress corrosion. Coatings 9, 424 (2019b)

EN 12603:2002: Glass in building. Procedures for goodness of fit and confidence intervals for Weibull distributed glass 
strength data. European Committee for Standardization, Brussels (2002)

ISO EN 16474-3:2013: Paints and varnishes - Methods of exposure to laboratory light sources. European Committee for Standardization, Brussels (2013)

Evans, A.G., Fuller, E.R.: Crack propagation in ceramic materials under cyclic loading conditions. Metall. Trans. 5, 27-33 (1974)

Grenet, L.: Mechanical strength of glass. Bulletin de la Société d'Encouragement pour l'Industrie Nationale 5(4), 838-848 (1899)

Gy, R.: Stress corrosion of silicate glass: review. J. Non-Cryst. Solids 316, 1-11 (2003)

Haldimann, M.: Fracture strength of structural glass elements - analytical and numerical modelling, testing and design. Thèse EPFL No 3671, Ecole Polytechnique Fédérale de Lausanne (EPFL) (2006)

Haldimann, M., Luible, A., Overend, M.: Structural Use of Glass. International Association for Bridge and Structural Engineering IABSE, Zurich (2008)

Jenkins, D.R., Mathey, R.G.: Hail impact testing procedure for solar collector covers. NBSIR; 82-2487, U.S. Dept. of Commerce, National Bureau of Standards. , Washington, DC (1982)

Kurkjian, C.R., Simpkins, P.G., Inniss, D.: Strength, degradation, and coating of silica lightguides. J. Am. Ceram. Soc. 76, 1106-1112 (1993)

Lindqvist, M., Louter, C., Lebet, J.P.: Edge-strengthening of structural glass with protective coatings. Key Eng. Mater. 488-489, 331-334 (2012)

Mariggiò, G., Dalle Vacche, S., Bongiovanni, R., Louter, C., Corrado, M.: Enhancing the design bending strength of new and aged glass with a functional coating. Glass Struct. Eng. 5, 135-146 (2020)
Michalske, T.A., Freiman, S.W.: A molecular mechanism for stress corrosion in vitreous silica. J. Am. Ceram. Soc. 66, 284-288 (1983)

Overend, M., Zammit, K.: A computer algorithm for determining the tensile strength of float glass. Eng. Struct. 45, 68-77 (2012)

Paris, P., Erdogan, F.: A critical analysis of crack propagation laws. J. Basic Eng. ASME 18, 528-534 (1963)

Trusiano, G., Vitale, A., Rizzello, M., Bonneaud, C., JolyDuhamel, C., Friesen, C.M., Bongiovanni, R.: Controlling perfluoropolyalkylether rearrangements at the surface of photocured networks. Eur. Polym. J. 121, 109285 (2019)

Vitale, A., Bongiovanni, R., Ameduri, B.: Fluorinated oligomers and polymers in photopolymerization. Chem. Rev. 115, 8835-8866 (2015)

Wang, B., Cunning, B.V., Park, S.Y., Huang, M., Kim, J.Y., Ruoff, R.S.: Graphene coatings as barrier layers to prevent the water-induced corrosion of silicate glass. ACS Nano 10, 9794-9800 (2016)

Wang, Z., Pakoulev, A., Pang, Y., Dlott, D.D.: Vibrational substructure in the oh stretching transition of water and HOD. J. Phys. Chem. A 108(42), 9054-9063 (2004)

Wei, M., Bowman, R.S., Wilson, J.L., Morrow, N.R.: Wetting properties and stability of silane-treated glass exposed to water, air, and oil. J. Colloid Interface Sci. 157(1), 154-159 (1993)

Wiederhorn, S.M.: Influence of water vapor on crack propagation in soda-lime glass. J. Am. Ceram. Soc. 50, 407-414 (1967)

Wiederhorn, S.M., Bolz, L.H.: Stress corrosion and static fatigue of glass. J. Am. Ceram. Soc. 53, 543-548 (1967)

Publisher's Note Springer Nature remains neutral with regard to jurisdictional claims in published maps and institutional affiliations. 